\title{
SARS-CoV-2 IgG Antibody and its Clinical Correlates in Convalescent Plasma Donors: An Indian Experience
}

\author{
PVSN Kiran Kumar ${ }^{1} \cdot$ Mithu Banerjee ${ }^{1}$ (1) $\cdot$ Archana Bajpayee $^{2} \cdot$ Saptarishi Mandal $^{2}$. \\ Prasenjit Mitra $^{3} \cdot$ Praveen Sharma $^{1} \cdot$ Sanjeev Misra $^{1} \cdot$ Pankaj Bhardwaj $^{4}$
}

Received: 18 February 2021 / Accepted: 23 September 2021 / Published online: 18 November 2021

(c) The Author(s), under exclusive licence to Association of Clinical Biochemists of India 2021

\begin{abstract}
SARS-CoV-2, a novel coronavirus, emerged a year ago in Wuhan, China causing a new pandemic. Convalescent plasma therapy has been applied previously to many infectious diseases and has shown a successful result. This study was planned to assess the Anti-SARS-CoV-2 IgG antibody levels in convalescent COVID-19 patients. In this study, serum samples from 210 persons infected by SARS-CoV-2, treated and discharged from the hospital were collected. Anti-SARS-CoV-2 IgG antibody levels
\end{abstract}

Mithu Banerjee

mithu.banerjee.3@gmail.com

PVSN Kiran Kumar

pvsnkirankumar@gmail.com

Archana Bajpayee

bajpayeea@aiimsjodhpur.edu.in

Saptarishi Mandal

dr.mandal@gmail.com

Prasenjit Mitra

prasy4u@gmail.com

Praveen Sharma

praveensharma55@gmail.com

Sanjeev Misra

director@aiimsjodhpur.edu.in

Pankaj Bhardwaj

pankajbhardwajde@gmail.com

1 Department of Biochemistry, All India Institute of Medical Sciences, Basni Phase -2 Jodhpur, Rajasthan, India

2 Deparment of Transfusion Medicine, All India Institute of Medical Sciences, Jodhpur, India

3 Deparment of Biochemistry, Post Graduate Institute of Medical Education \& Research, Chandigarh, India

4 Department of Community Medicine \& Family Medicine, All India Institute of Medical Sciences, Jodhpur, India were detected using a chemiluminescence assay. A directory of convalescent plasma donors was created. AntiSARS-CoV-2 IgG antibody levels vary substantially in the study population with a mean of $51.2 \mathrm{AU} / \mathrm{ml}$. On comparing the serum anti-SARS-CoV-2 IgG antibody levels, a significant difference was observed between the subjects who had cough and those who did not $(\mathrm{p}=0.0004)$. Similar significant findings were found with total protein and globulin levels on comparing the individuals with different antibody status (positive, negative and equivocal). The middle-aged and old age people had high Ab titres compared to younger individuals and the duration of the hospital stay was found to be positively correlated with the anti-SARS-CoV-2 IgG antibody. Cough, age and duration of the hospital stay was found to play a significant role in the development of Anti-SARS-CoV-2 IgG levels. Further, the data suggests that blood groups have a lesser impact on the severity of disease and the development of antibodies. Patients who present with the cough are more likely to develop antibodies.

Keywords Convalescent plasma Therapy · IgG antibody * COVID-19 - SARS- Co-V-2

\section{Introduction}

SARS-CoV-2, a novel coronavirus belonging to the group of beta coronaviruses, emerged a year ago in Wuhan, China causing a new pandemic. Since then, the world has witnessed, approximately 197,073,011 infected cases with $4,210,030$ deaths (as of 31 July 2021) [1]. In India, the 1st case was detected on January 30, 2020. India has the second-largest number of coronavirus cases in the world after the US. From recent studies, it has emerged that the SARS- 
CoV-2 infection may also result in asymptomatic and mild infections, leading to obscuring of the actual number of cases [2]. Although testing for the SARS-CoV-2 in India has been significantly ramped up achieving one million tests in a single day on 21 August, the tests performed are way under the required testing number when compared to the population of 1.4 billion. Due to this under testing, the majority of the cases remain undetected who are either asymptomatic or have a mild disease [3].

For more than a decade, convalescent plasma (CP) therapy has been applied previously to many infectious diseases. It has shown a successful result in past coronavirus diseases like the Middle East respiratory syndrome (MERS) and Severe acute respiratory syndrome (SARS). Therefore, both the United States Food and Drug Administration (USFDA) and the Indian Council of Medical Research (ICMR) had approved the use of CP in COVID19 patients in the early phase of the Pandemic. ICMR sponsored PLACID trial was published recently [4]. This trial recruited 462 patients from 39 tertiary care hospitals across India. This study did not report any benefit in allcause mortality or progress to a severe course in patients with moderate disease. However, a higher proportion of patients in the intervention arm showed improvement in the resolution of dyspnoea and fatigue. The study also concluded that high-titre plasma may be more beneficial than low-titre plasma for COVID-19 patients. Based on this study the $\mathrm{CP}$ continued to find a place in the recommended guidelines, in 'off label' use [5]. A UK based doubleblinded RECOVERY trial involving 5000 patients was published recently [6]. The results of the trial reported that high titre convalescent plasma transfusion did not reduce mortality or improve patient outcome. After the RECOVERY trial results, the national task force of the ICMR, along with experts from the Health Ministry has dropped the use of convalescent plasma from the recommended treatment guidelines for COVID-19 [7].

In past, seroprevalence studies of many diseases have been found to reflect the proportion of people exposed to the infection, which reveals the true burden of the disease in the community. These studies include the detection of specific antibodies to the virus protein. Protection specific Abs, including immunoglobulin G (IgG) Abs and neutralizing Abs (NAbs), are produced by B cells after infection with the virus, which can block the virus from entering the host cells and prevent reinfection. A recent study reported acute antibody responses to SARS-CoV-2 in 285 patients with COVID-19 [8]. Within 19 days of symptom onset, $100 \%$ of patients tested positive for antiviral immunoglobulin-G (IgG). Seroconversion for $\operatorname{IgG}$ and $\operatorname{IgM}$ occurred simultaneously or sequentially. Both IgG and IgM titres plateaued within 6 days of seroconversion [8]. There are many population-based studies on the seroprevalence of antibodies against SARS-CoV-2 in different countries like France, Italy and Switzerland but none of them have an available database for donors with high antibody titers for convalescent plasma therapy [9]. Similar population-based studies were also started in the United States for the use of convalescent plasma as a treatment modality [10].

Although neutralising antibody titres should be done before administering $\mathrm{CP}$, it is not feasible in all tertiary care centres for the want of biosafety level -3 facility, which are far and few and restricted primarily to research institutes only. The New York Blood Centre \& the ConCOVID group from Netherland have both shown a good correlation between commercial serological assays and neutralisation assays [11, 12]. Different commercial platforms being used for the estimation of SARS-CoV-2 IgG antibodies and lack of harmonisation between assays is a hurdle in the estimation of IgG SARS CoV-2 antibodies and adoption of $\mathrm{CP}$ as a standard of care in the treatment of COVID-19.

Previous studies have indicated that the blood group antigens found in erythrocytes and other tissues interact with microorganisms such as bacteria, viruses, parasites, and fungi. Differences in blood group antigen expression can increase or decrease host susceptibility to many infections. Infection with Hepatitis C virus, human immunodeficiency virus, and SARS are associated with human blood groups [13-15]. Clinical studies have also been conducted examining the relationship between SARSCoV-2 and blood groups [16, 17].

The present study was planned to assess the IgG antibody levels for SARS-CoV-2 spike protein S1/S2 in treated and recovered patients from COVID-19 and to prepare a database of potential donors for convalescent plasma therapy in a tertiary health care centre in the North-Western region of India.

\section{Materials and Methods}

This was a cross-sectional study conducted at All India Institute of Medical Sciences (AIIMS), Jodhpur between 11 July and 25 September 2020. A total of 210 COVID-19 patients (tested positive by RT-PCR) were recruited. Patients who had recovered were counselled in person before discharge from wards on the uses of convalescent plasma \& encouraged to donate plasma. Patients were counselled on telephone as well. All participants had given their written informed consent before participating in the study and their anonymity was preserved. The study was performed as per the ethical guidelines established in the declaration of Helsinki and was approved by the institutional ethics committee (AIIMS/IEC/2020/3202). 
A total of $3.5 \mathrm{ml}$ of blood was drawn, serum was separated and stored at $-80{ }^{\circ} \mathrm{C}$, and was defrosted before testing. Blood grouping was done with the standard tube method. CBC was done on a three-part Sysmex XP-100 automated analyser. Anti-SARS-CoV-2 IgG antibody against S1/S2 antigens of SARS-CoV-2 was detected using both FDA and ICMR approved fully automated chemiluminescence analyser Liaison XL (DiaSorin, Italy). As per the kit literature the estimated sensitivity \& specificity of this Anti-SARS-CoV-2 IgG antibody test by Liaison XL (DiaSorin, Italy) was 97.4\% (95\% CI 86.8\%-99.5\%) \& $98.5 \%(95 \%$ CI $97.5 \%-99.2 \%)$ in individuals after 15 or more days of a positive RT PCR test. The positive agreement in comparison to plaque reduction neutralization test (PRNT) is $94.4 \%$ (95\% CI 88.8\%-97.2\%) and negative agreement $97.8 \%$ (95\% CI 94.4\%-99.1\%). Titers with < 12.0 AU/mL was regarded as negative, 12.0-15.0 AU/mL was taken as equivocal and $>15.0 \mathrm{AU} / \mathrm{mL}$ was regarded as positive for the antibodies. The average intra-assay imprecision was a $2.8 \%$ coefficient of variation $(2.8 \% \mathrm{CV})$ (range $2.0-3.4 \% \mathrm{CV}$ ), and total-assay imprecision averaged $3.2 \% \mathrm{CV}$ (range 2.7-3.9\% CV) [18].

\section{Statistical Analysis}

The data collected were analysed using Microsoft Excel and Stata version 14 for windows. The data are expressed as mean, median and range. Categorical variables were calculated as frequency and percentage, continuous variables were represented as mean (SD). The normality of the parameters was checked using the Shapiro-Wilks test and found to be non-parametric. Mann Whitney U test and Chisquare test were used to calculate the statistical differences between continuous variables and categorical variables respectively. Multivariable analysis was performed for the clinical measures and symptomatic profiles using logistic regression. The Kruskal-Wallis test was used to compare between 3 or more groups. Spearman correlation test and Bonferroni correction for multiple testing were used to examine the relationship between anti-SARS-CoV-2 IgG antibody levels and other clinical measures. A p-value of $<0.05$ was considered statistically significant.

\section{Results}

The demographic profiles, biochemical profile (AntiSARS-CoV-2 IgG antibody levels, total protein, albumin and globulin), clinical symptom profiles (throat pain, cough, fever, dyspnoea, muscle/ body pain and loss of taste/smell), complete blood count and duration of hospitalisation were observed in all subjects (Tables 1,2).

The mean (SD) age of the study population was 35.6 (9.3) years while the median and range were 36 and 18-58 years respectively. Among the study subjects, 200 $(95 \%)$ were males with a mean age of 36.2 years and 10 $(5 \%)$ were females with a mean age of 28.1 years.
Table 1 Demographic and clinical laboratory data of the study population

\begin{tabular}{|c|c|c|c|c|}
\hline \multirow[t]{2}{*}{ Variables } & \multicolumn{4}{|c|}{ Study population $(\mathrm{n}=210)$} \\
\hline & $\mathrm{n}(\%)$ & Mean (SD) & Median & Range \\
\hline \multicolumn{5}{|l|}{ Demographic data } \\
\hline Age (In years) & - & $35.64(9.55)$ & 46.82 & $18-58$ \\
\hline \multicolumn{5}{|l|}{ Gender } \\
\hline Males & $204(97)$ & - & - & - \\
\hline Females & $6(3)$ & - & - & - \\
\hline \multicolumn{5}{|l|}{ Clinical laboratory data } \\
\hline Anti-SARS-CoV-2 IgG (AU/mL) & - & $51.29(50.41)$ & 31.69 & $3.8-206$ \\
\hline Total protein $(\mathrm{gm} / \mathrm{dL})$ & - & $7.42(0.49)$ & 7.60 & $4.8-8.58$ \\
\hline Albumin $(\mathrm{gm} / \mathrm{dL})$ & - & $4.41(0.36)$ & 4.53 & $2.26-5.16$ \\
\hline Globulin (gm/dL) & - & $3(0.35)$ & 3.06 & $2.12-4.31$ \\
\hline \multicolumn{5}{|c|}{ Haematological profile of plasma donors $(n=97)$} \\
\hline $\mathrm{Hb}(\mathrm{gm} / \mathrm{dL})$ & - & $15.19(1.5)$ & 15.1 & $12.1-20.1$ \\
\hline Platelets $\left(* 10^{3}\right)$ & - & $259(65)$ & 260 & $75-451$ \\
\hline Monocytes & - & $10.8(4.9)$ & 9.7 & $4.4-44.3$ \\
\hline Neutrophils & - & $52(8)$ & 52.15 & $38.1-79.5$ \\
\hline Lymphocytes & - & $36(7.5)$ & 36.75 & $14.9-50.5$ \\
\hline Neutrophil-to-lymphocyte ratio (NLR) & - & $1.57(0.65)$ & 1.4 & $0.78-5.35$ \\
\hline Total leucocyte count (TLC) & - & $7850(1748)$ & 7650 & $1300-13,200$ \\
\hline
\end{tabular}


Table 2 The frequency of symptoms \& other clinical variables of the study population during the course of infection

\begin{tabular}{|c|c|c|c|}
\hline \multicolumn{4}{|l|}{ Clinical and symptomatic profile Study Population $(n=210)$} \\
\hline Clinical variables & Mean (SD) & Median & Range \\
\hline Duration of hospital Stay/ home quarantine (days) & $11.4(4.74)$ & 10.72 & $5-36$ \\
\hline Day of antibody test post RT-PCR negative status (days) & $41.48(27.06)$ & 60.24 & $13-214$ \\
\hline Symptomatic profile & & & Present $(\%)$ \\
\hline Throat Pain & & & $180(85.7)$ \\
\hline Cough & & & $143(68)$ \\
\hline Fever & & & $155(73.8)$ \\
\hline Muscle/Body pain & & & $49(23.3)$ \\
\hline Dyspnoea & & & $32(15.2)$ \\
\hline Diarrhoea & & & $13(6.1)$ \\
\hline Loss of Smell/Taste & & & $73(34.7)$ \\
\hline
\end{tabular}

The mean levels of anti-SARS-CoV-2 IgG antibody levels of the study population were $51.2 \mathrm{AU} / \mathrm{ml}$, while the median and range were 37.15 and 3.8-206 AU/ml respectively. Similarly, the mean, median and range of the biochemical parameters were represented in Table 1. Out of the total study population, $145(69 \%)$ tested positive, 55 (26\%) tested negative and $10(5 \%)$ tested equivocal for Anti-SARS-CoV-2 IgG antibody levels. On analysing the symptoms, the maximum number of study subjects were having throat pain $(85.7 \%)$, fever $(73.8 \%)$ and cough $(68 \%)$. The mean (SD) of the number of days of hospitalisation or home quarantine was 11.4 (4.6) days, while the median and range were 11 days and 5-36 days respectively. Similarly, the mean (SD) of other clinical measures, like the number of days after PCR negativity after which antibody level was estimated as 41.8 (28.4), whereas median and range were 36 days and 13-214 days respectively (Table 2). Out of these 145 positively tested patients, 97 patients donated plasma. On comparing the neutrophilto-lymphocyte ratio (NLR) of these 97 patients with the Anti-SARS-CoV-2 IgG antibody levels, there was a nonsignificant positive correlation $(\mathrm{r}=0.28, \mathrm{p}=0.4)$ (Table 3). A significant weak negative correlation was found between the NLR and the number of days after PCR negativity, after which the antibody level was estimated $\left(r_{s}\right.$ $=-0.2, \mathrm{p}=0.01$ ) (Table 4).

On comparing the serum anti-SARS-CoV-2 IgG antibody levels between individuals with and without symptoms, a significant increase in the antibody levels was observed between the subjects having cough $(\mathrm{p}=0.0004)$ (Table 5). Further, on comparing the status of the antibodies (positive, negative and equivocal) with the clinical and demographic profiles a significantly higher antibody level was found between the subjects who had cough and those who did not $\left(\chi^{2}-11.89, \mathrm{p}=0.003\right)$ (Table 6). The total protein and globulin levels have significantly differed between different antibody status $\left(\chi^{2}-10.15, \mathrm{p}=0.006\right.$ and $\chi^{2}-7.01, \mathrm{p}=0.03$ ) (Fig. 1). Logistic regression was run to understand the effects of the clinical features and symptoms on development of antibodies. The number of days of hospital stay and cough significantly predicted the antibody development $(p=0.025$ and $p=0.016$ respectively).

On correlation analysis, no significant correlation was found between Anti-SARS-CoV-2 IgG antibody levels and biochemical parameters (after the Bonferroni correction for multiple testing) (Table 3). The serum Anti-SARS-CoV-2 IgG antibody levels showed a nonsignificant positive correlation with both duration of hospital stay/home quarantine $(p=0.2)$ and with the number of days after which the antibody test was done $(\mathrm{p}=0.3)$.

In the total study population, $83(40 \%)$ were having $\mathrm{O}$ positive blood group, $69(33 \%)$ were having B positive blood group, 45 (21\%) were having A positive blood group \& $13(6 \%)$ were having AB positive blood group. Out of all the positively tested individuals (145) for antibodies, 57 (39.3\%) had $\mathrm{O}$ positive blood group. On comparing the blood groups with the antibody status and other clinical parameters, no significant difference was found.

\section{Discussion}

Ever since WHO declared COVID-19 as a global pandemic, the whole world has been looking for the development of an effective treatment or vaccine against SARSCoV-2 infection. Since then, convalescent plasma therapy has emerged as one of the treatment plans for SARS-CoV2 infection. Convalescent plasma therapy, classic adaptive immunotherapy, has been applied to the prevention and treatment of many infectious diseases for more than a decade. Over the past decades, convalescent plasma 
Table 3 Comparison of frequency of symptoms \& other clinical variables with different antibody status (negative, equivocal and positive) of the study population
Clinical Details

\section{Gender}

Males

Females

Throat pain

Yes

No

Cough

Yes

No

Fever

Yes

No

Muscle/Body pain

Yes

No

Dyspnoea

Yes

No

Diarrhoea

Yes

No

Loss of Smell/Taste

Yes

No

Co-morbidities DM*

Present

Absent

HTN $^{*}$

Present

Absent

Both $\mathrm{DM}^{*} \& \mathrm{HTN}^{*}$

HTN

DM

Both

None

Smoking/Alcohol

Smoking

Alcohol

Both

None

Blood Group

$\mathrm{A}+$
$\mathrm{A}-$
$\mathrm{B}+$
$\mathrm{AB}+$
$\mathrm{O}+$
$\mathrm{O}-$

Antibody status

Negative $(<12)$

Equivocal (12-15)

Positive (> 15)

52

10

0

142

49

23

37

18

16

39

$\chi^{2} \quad \mathrm{p}$

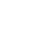

3

123

$0.87 \quad 0.64$

22

108

11.89

0.003

37

110

1.73

0.42

35

33

4.08

10

112

25

2.51

48

10

120

9

3.90

53

2

8

136

51

0.11

0.94

36

94

16

0.14

0.92

122

13

0.15

0.91

125

48

8

13

0.88

0.9

16

7

109

43

1

7

1.6

0.9

31

14

93

37

2

1

7

$7 \quad 4$

30

9.5

0.4

*DM Diabetes melitus, HTN hypertension 

SARS-CoV-2 IgG levels of the study population (with and with out symptoms \& treatment with remdesivir) during the course of infection
Table 4 Comparison of Anti-

\begin{tabular}{|c|c|c|c|}
\hline Variables & $\mathrm{n}$ & Anti-SARS-CoV-2 IgG levels Median (range) & p-value \\
\hline \multicolumn{4}{|c|}{ Throat Pain } \\
\hline Yes & 180 & $31.7(3.08-187)$ & \multirow[t]{2}{*}{0.11} \\
\hline No & 30 & $40.5(38-206)$ & \\
\hline \multicolumn{4}{|l|}{ Cough } \\
\hline Yes & 143 & $45.25(3.8-206)$ & \multirow[t]{2}{*}{0.0004} \\
\hline No & 67 & $23.75(3.8-182)$ & \\
\hline \multicolumn{4}{|l|}{ Fever } \\
\hline Yes & 155 & $37.9(3.8-206)$ & \multirow[t]{2}{*}{0.46} \\
\hline No & 55 & $31.4(3.8-200)$ & \\
\hline \multicolumn{4}{|c|}{ Muscle/Body pain } \\
\hline Yes & 49 & $35.05(3.8-183)$ & \multirow[t]{2}{*}{0.7} \\
\hline No & 161 & $37.15(3.8-206)$ & \\
\hline \multicolumn{4}{|l|}{ Dyspnoea } \\
\hline Yes & 32 & $35.07(3.8-206)$ & \multirow[t]{2}{*}{0.5} \\
\hline No & 178 & $29.1(3.8-175)$ & \\
\hline \multicolumn{4}{|l|}{ Diarrhoea } \\
\hline Yes & 13 & $34.05(3.8-182)$ & \multirow[t]{2}{*}{0.9} \\
\hline No & 197 & $36.15(3.8-206)$ & \\
\hline \multicolumn{4}{|c|}{ Loss of Smell / Taste } \\
\hline Yes & 73 & $36.9(3.8-206)$ & \multirow[t]{2}{*}{0.42} \\
\hline No & 137 & $32.4(3.8-195)$ & \\
\hline \multicolumn{4}{|c|}{ Treatment with remdesivir } \\
\hline Yes & 23 & $56.5(15.4-206)$ & \multirow[t]{2}{*}{0.13} \\
\hline No & 187 & $32.5(3.8-177)$ & \\
\hline
\end{tabular}

therapy was successfully used in the treatment of SARS, MERS, and the $2009 \mathrm{H} 1 \mathrm{~N} 1$ pandemic with satisfactory efficacy and safety [19-21]. Positive tests for IgG, IgM, and IgA are generally described as $>1.0$ arbitrary unit $/ \mathrm{mL}$ or AU/mL [14]. Values for IgG antibodies $>6.5 \mathrm{AU} / \mathrm{mL}$ correspond to an antibody titer of approximately $>1: 320$ and $\mathrm{IgG}$ values $>20 \mathrm{AU} / \mathrm{mL}$ correspond to titers $>$ 1:1000. An IgG antibody titer of $>1: 320$ has been recommended by the FDA as a threshold for determining if convalescent plasma should be used in a patient [15]. The FDA also recommends an antibody titer of $1: 160$, but a titer of 1:80 may be acceptable if another matched unit is not available [16]. Currently, there is insufficient data about how titer levels correlate with viral clearance and even the roles of humoral and cellular immune responses during the infection. In this study, we made a database of potential donors for convalescent plasma therapy by assessing the Anti-SARS-CoV-2 IgG levels in treated and recovered patients from COVID-19.

Quantification of Anti-SARS-CoV-2 IgG antibody levels in recovered or treated patients is a key tool for the determination of immunity of the population to SARSCoV-2 infection. Results of our study suggest that majority of the subjects who have recovered from SARS-CoV-2 infection had positive antibody levels. These findings were similar to many other seroprevalence studies [17]. Although most of the study subjects have a similar duration of hospital stay, the serum antibody titres showed significant variation. Around $40 \%$ of the study population failed to develop a significant antibody titre against the SARSCoV-2. This may be due to different immune response in individuals against COVID-19 around the globe. Similarly, few individuals had developed very high titres of AntiSARS-CoV-2 IgG levels within 20 days with the same course of infection as of individuals who failed to develop antibodies. These findings were similar to the study done by $\mathrm{Wu}$ et al., where $30 \%$ of the study population who had recovered from SARS-CoV-2 infection failed to develop the antibodies against the virus [18]. These results may suggest that some other immune factors may play role in the development of the Anti-SARS-CoV-2 IgG in recovered patients. Whether these individuals with low antibody titres are at risk of reinfection has to be explored in future studies. Logistic regression has shown that the duration of the hospital stay has correlated with the antibody status and patients having cough as a symptom had developed positive antibody status. The results of the regression were contradictory to the results of previous studies where the duration of hospital stay negatively correlated with the antibody status [19]. A negative correlation in our study 
Table 5 Correlation of AntiSARS-CoV-2 IgG levels with clinical variables
Table 6 Correlation of NLR with the clinical variables of convalescent plasma donors $(\mathrm{n}=97)$

\begin{tabular}{lll}
\hline Variables study population $(\mathrm{n}=210)$ & \multicolumn{2}{l}{ Anti-SARS-CoV-2 IgG levels } \\
\cline { 2 - 3 } & $\mathrm{r}_{\mathrm{s}}$ & $\mathrm{p}$-value \\
\hline Age & 0.0185 & 0.7 \\
Duration of hospital Stay/ home quarantine & 0.084 & 0.2 \\
Day of antibody test post RT-PCR negative status & -0.06 & 0.3 \\
Total Protein & -0.012 & 0.8 \\
Albumin & -0.015 & 0.8 \\
Globulin & 0.005 & 0.9 \\
\hline
\end{tabular}

\begin{tabular}{lll}
\hline Variables study population $(\mathrm{n}=97)$ & $\mathrm{NLR}$ & $\mathrm{p}$-value \\
\cline { 2 - 3 } & $\mathrm{r}_{\mathrm{s}}$ & 0.2 \\
\hline Age & 0.13 & 0.6 \\
Duration of hospital Stay/ home quarantine & -0.05 & $\mathbf{0 . 0 1}$ \\
Day of antibody test post RT-PCR negative status & -0.25 & 0.4 \\
IgG & 0.08 & 0.2 \\
TLC vs IgG antibodies & -0.15 &
\end{tabular}

*NLR Neutrophil-Lymphocyte Ratio, TLC Total lymphocyte count

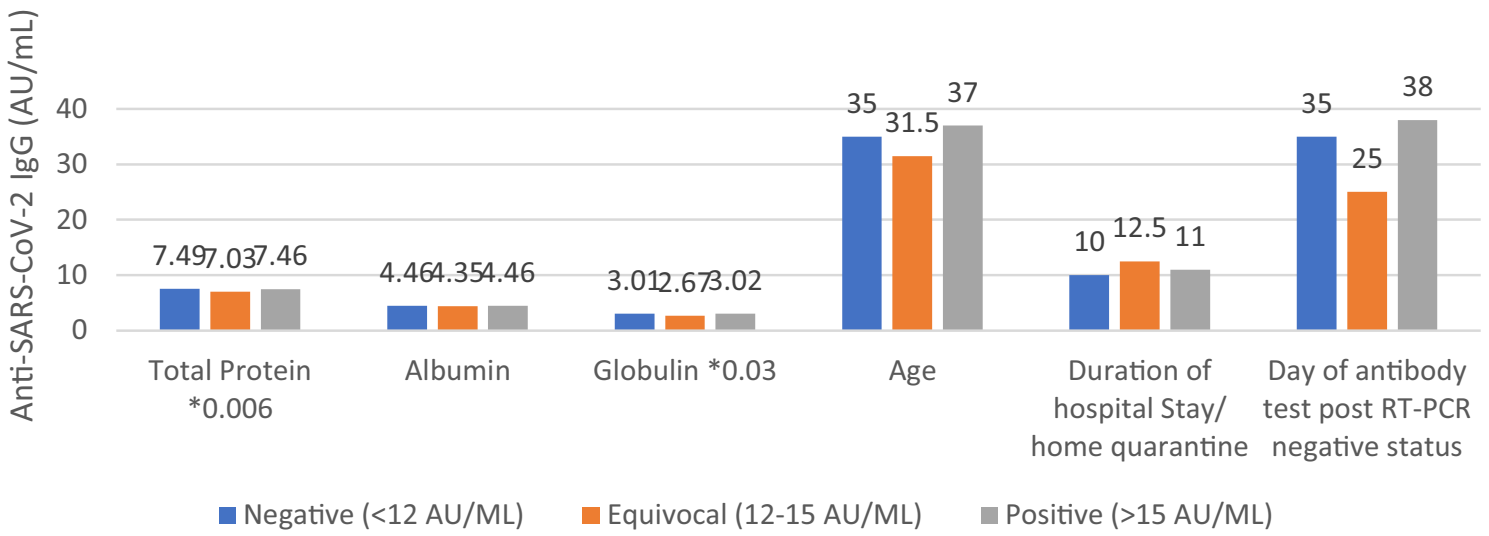

Fig. 1 Comparison of different clinical variables against the negative, equivoval and positive antibody levels $(n=210)$

between duration of hospital stay and antibody status could be attributed to the fact that lower antibody levels meant more severe infection hence the hospital stay was prolonged.

According to a recent study by the American Society of Haematology, individuals with blood type $O$ may have the lowest risk of infection whereas individuals with $\mathrm{A}$ and $\mathrm{AB}$ may have an increased risk of severe clinical outcomes [20]. In this study, almost all the blood groups have a similar duration of hospital stay and the Rh-positive blood groups were associated with higher antibody levels. The $\mathrm{Rh}+$ association with disease positivity appears to be a novel finding and warrants further investigation. Given the relative rarity of $\mathrm{Rh}$-negative blood types, these could not be ruled out by our patient numbers in this study. Our data suggest that blood groups may have a lesser impact on the severity and the development of the antibodies against the SARS-CoV-2. Similarly, comorbidities like diabetes mellitus (DM) and hypertension (HTN) did not have any significant effect on the development of antibodies, which is in line with a recent seroprevalence study on a Spanish population. [28].

Recent studies indicate neutrophil/lymphocyte ratio (NLR) as a powerful prognostic factor for COVID-19 [29]. NLR was calculated by dividing the absolute neutrophil count by the lymphocyte count. In this study, we have compared both the NLR, an indicator of innate immunity, and $\mathrm{IgG}$, an indicator of acquired immunity. A significnat 
negative correlation of NLR with the number of days post RT-PCR negative status suggests that inflammation decreases with time. A high NLR connotes more severe disease which led to an enhanced acquired immunological response hence higher antibody levels. Our findings are similar to the other studies indicating that $\mathrm{IgG}$ response is also associated with the development of other innate immunity-related markers such as NLR [30].

Like other coronavirus infections, in SARS-CoV-2 infection, age played a major role in severity [31, 32]. In a recent study by Yang et al., patients aged 19-30 years exhibited lower levels of SARS-CoV-2 IgG antibodies than children and older adults [33]. However, in this study, the middle-aged and old people had high Ab titres compared to younger individuals. The exact mechanisms underlying the different SARS-CoV-2 immune responses based on age remain unclear. Age-related quantitative and qualitative changes in the immune system affect cells and soluble mediators of both the innate and adaptive immune responses within lymphoid and non-lymphoid peripheral tissues. These changes determine not only the susceptibility to infections but also disease progression and clinical outcomes thereafter [34]. In this study, the symptom cough was found to play a significant role in the anti-SARS-CoV$2 \mathrm{IgG}$ levels. Similar results were seen with the throat pain, cough and fever in other studies on recovered patients [35]. The role of treatment with remdesivir on anti-SARS-CoV-2 IgG levels is still not fully explored. In our sudy, there was no significant difference between patients who received remdesivir and who did not. Further studies on immunological aspects of antiviral drugs may give a clear insight into the development of protective antibodies.

There are several operational challenges for the implementation of CP on a mass scale apart from the controversial evidence of its benefit in treating COVID-19. Centralised antibody estimation titre and harmonisation of seroassays should be undertaken to build registries of $\mathrm{CP}$ donors.

Multiple barriers exist amongst convalescent COVID-19 patients regarding the donation of plasma. A lurking fear of visiting the hospital amid an epidemic, scare of the procedure of apheresis, fear of waning immunity on donating plasma and reinfection are a few of them. This problem is further compounded by lockdowns \& restriction on mobility during pandemics [36].

\section{Conclusion}

Among the patients who recovered from SARS-CoV-2 infection, Anti-SARS-CoV-2 IgG antibody levels appeared to vary substantially. The development of the antibodies positively correlated with the age and duration of the hospital stay. Further, the data suggests that blood groups may have a lesser impact on the severity and the development of the antibodies. The potential clinical implications of these findings for convalescent plasma therapy, vaccine development and future protection from infection are still needed to be explored.

To the best of our knowledge, this is the first study in the western Indian population that has assessed Anti-SARSCoV-2 IgG antibody levels in SARS-CoV-2 recovered patients. This study is preliminary and has several limitations. First, the viral loads during the disease course have not been taken into consideration. Second, we did not measure the neutralising antibodies hence we were unable to evaluate the effect of viral clearance on antibodies.

\section{References}

1. Coronavirus Update (Live): $81,144,994$ Cases and 1,771,981 Deaths from COVID-19 Virus Pandemic - Worldometer [Internet]. [cited 2020 Dec 28]. Available from: https://www.world ometers.info/coronavirus/

2. Oran DP, Topol EJ. Prevalence of asymptomatic SARS-CoV-2 infection: a narrative review. Ann Intern Med. 2020;173(5): $362-7$.

3. Covid-19: Govt reaches target of testing a million people per day - india news - Hindustan Times. [cited 2020 Dec 28]. Available from: https://www.hindustantimes.com/india-news/govt-reachestarget-of-testing-a-million-people-in-a-day/story-6G33zy5k3V Ti5ZF2u7r4bP.html

4. Agarwal A, Mukherjee A, Kumar G, Chatterjee P, Bhatnagar T, Malhotra P. Convalescent plasma in the management of moderate covid-19 in adults in India: open label phase II multicentre randomised controlled trial (PLACID Trial). BMJ. 2020;371:m3939.

5. ClinicalManagementProtocolforCOVID19.pdf [Internet]. [cited 2021 Jun 6]. Available from: https://www.mohfw.gov.in/pdf/ ClinicalManagementProtocolforCOVID19.pdf

6. Liu STH, Aberg JA. Convalescent plasma in patients hospitalised with COVID-19. Lancet Lond Engl. 2021;397(10289):2024-5.

7. COVID_Management_Algorithm_17052021.pdf [Internet]. [cited 2021 Jun 6]. Available from: https://www.icmr.gov.in/pdf/ covid/techdoc/COVID_Management_Algorithm_17052021.pdf

8. Long Q-X, Liu B-Z, Deng H-J, Wu G-C, Deng K, Chen Y-K, et al. Antibody responses to SARS-CoV-2 in patients with COVID-19. Nat Med. 2020;26(6):845-8.

9. Stringhini S, Wisniak A, Piumatti G, Azman AS, Lauer SA, Baysson $\mathrm{H}$, et al. Seroprevalence of anti-SARS-CoV-2 IgG antibodies in Geneva, Switzerland (SEROCoV-POP): a population-based study. Lancet Lond Engl. 2020;396(10247):313-9.

10. Max Healthcare Insititute Limited. A Phase II, Open Label, Randomized Controlled Trial to Assess the Safety and Efficacy of Convalescent Plasma to Limit COVID-19 Associated Complications [Internet]. clinicaltrials.gov; 2020 Jul [cited 2020 Dec 23]. Report No.: NCT04374487. Available from: https://clin icaltrials.gov/ct2/show/NCT04374487

11. Luchsinger LL, Ransegnola BP, Jin DK, Muecksch F, Weisblum Y, Bao W, et al. Serological assays estimate highly variable SARS-CoV-2 neutralizing antibody activity in recovered COVID-19 patients. J Clin Microbiol. 2020;58(12). 
12. GeurtsvanKessel CH, Okba NMA, Igloi Z, Embregts CWE, Laksono BM, Leijten L, et al. Towards the next phase: evaluation of serological assays for diagnostics and exposure assessment. medRxiv. 2020;2020.04.23.20077156.

13. Behal R, Jain R, Behal KK, Dhole TN. Variation in the host ABO blood group may be associated with susceptibility to hepatitis $\mathrm{C}$ virus infection. Epidemiol Infect. 2010;138(8):1096-9.

14. Onsten TGH, Callegari-Jacques SM, Goldani LZ. The higher frequency of blood group b in a brazilian population with HIV infection. Open AIDS J. 2013;7:47-50.

15. Guillon P, Clément M, Sébille V, Rivain J-G, Chou C-F, RuvoënClouet $\mathrm{N}$, et al. Inhibition of the interaction between the SARS$\mathrm{CoV}$ spike protein and its cellular receptor by anti-histo-blood group antibodies. Glycobiology. 2008;18(12):1085-93.

16. Wu Y, Feng Z, Li P, Yu Q. Relationship between ABO blood group distribution and clinical characteristics in patients with COVID-19. Clin Chim Acta Int J Clin Chem. 2020;509:220-3.

17. Zhao J, Yang Y, Huang H, Li D, Gu D, Lu X, et al. Relationship between the ABO Blood Group and the COVID-19 Susceptibility. Clin Infect Dis Off Publ Infect Dis Soc Am. 2020

18. Bonelli F, Sarasini A, Zierold C, Calleri M, Bonetti A, Vismara $\mathrm{C}$, et al. Clinical and analytical performance of an automated serological test that identifies S1/S2-neutralizing IgG in COVID19 patients semiquantitatively. J Clin Microbiol. 2020;58(9): e01224-e1320.

19. Cheng Y, Wong R, Soo YOY, Wong WS, Lee CK, Ng MHL, et al. Use of convalescent plasma therapy in SARS patients in Hong Kong. Eur J Clin Microbiol Infect Dis Off Publ Eur Soc Clin Microbiol. 2005;24(1):44-6.

20. Zhou B, Zhong N, Guan Y. Treatment with convalescent plasma for influenza A (H5N1) infection. N Engl J Med. 2007;357(14): $1450-1$.

21. Hung IF, To KK, Lee C-K, Lee K-L, Chan K, Yan W-W, et al. Convalescent plasma treatment reduced mortality in patients with severe pandemic influenza A (H1N1) 2009 virus infection. Clin Infect Dis Off Publ Infect Dis Soc Am. 2011;52(4):447-56.

22. Antibody Detection I National COVID-19 Convalescent Plasma Project [Internet]. [cited 2020 Dec 28]. Available from: https:// ccpp19.org/healthcare_providers/virology/antibodies.html

23. Research $\mathrm{C}$ for $\mathrm{BE}$ and. Recommendations for Investigational COVID-19 Convalescent Plasma. FDA [Internet]. 2020 [cited 2020 Dec 28]; Available from: https://www.fda.gov/vaccinesblood-biologics/investigational-new-drug-ind-or-device-exemp tion-ide-process-cber/recommendations-investigational-covid19-convalescent-plasma

24. Burgess S, Ponsford MJ, Gill D. Are we underestimating seroprevalence of SARS-CoV-2? BMJ. 2020;370:m3364.

25. Wu F, Wang A, Liu M, Wang Q, Chen J, Xia S, et al. Neutralizing antibody responses to SARS-CoV-2 in a COVID-19 recovered patient cohort and their implications. medRxiv. 2020;2020.03.30.20047365.
26. Wu F, Liu M, Wang A, Lu L, Wang Q, Gu C, et al. Evaluating the association of clinical characteristics with neutralizing antibody levels in patients who have recovered from mild COVID-19 in Shanghai, China. JAMA Intern Med. 2020;180(10):1356-62.

27. Studies offer new evidence for possible link between blood type and COVID-19 susceptibility: Individuals with blood type O may have lowest risk of infection; individuals with $\mathrm{A}$ and $\mathrm{AB}$ may have increased risk of severe clinical outcomes [Internet]. ScienceDaily. [cited 2020 Dec 28]. Available from: https://www. sciencedaily.com/releases/2020/10/201014161544.htm

28. Garcia-Basteiro AL, Moncunill G, Tortajada M, Vidal M, Guinovart C, Jiménez A, et al. Seroprevalence of antibodies against SARS-CoV-2 among health care workers in a large Spanish reference hospital. Nat Commun [Internet]. 2020 [cited 2020 Dec 28];11. Available from: https://www.ncbi.nlm.nih.gov/ pmc/articles/PMC7343863/

29. Liu J, Liu Y, Xiang P, Pu L, Xiong H, Li C, et al. Neutrophil-tolymphocyte ratio predicts critical illness patients with 2019 coronavirus disease in the early stage. J Transl Med. 2020;18(1):206.

30. Zhang B, Zhou X, Zhu C, Song Y, Feng F, Qiu Y, et al. Immune Phenotyping Based on the neutrophil-to-lymphocyte ratio and IgG level predicts disease severity and outcome for patients with COVID-19. Front Mol Biosci [Internet]. 2020 [cited 2020 Dec 28];7. Available from: https://www.frontiersin.org/articles. Doi: https://doi.org/10.3389/fmolb.2020.00157/full\#B6

31. Peiris JSM, Chu CM, Cheng VCC, Chan KS, Hung IFN, Poon LLM, et al. Clinical progression and viral load in a community outbreak of coronavirus-associated SARS pneumonia: a prospective study. Lancet Lond Engl. 2003;361(9371):1767-72.

32. Hong K-H, Choi J-P, Hong S-H, Lee J, Kwon J-S, Kim S-M, et al. Predictors of mortality in Middle East respiratory syndrome (MERS). Thorax. 2018;73(3):286-9.

33. Yang HS, Costa V, Racine-Brzostek SE, Acker KP, Yee J, Chen $\mathrm{Z}$, et al. Association of age with SARS-CoV-2 antibody response. JAMA Netw Open. 2021;4(3):e214302.

34. Bajaj V, Gadi N, Spihlman AP, Wu SC, Choi CH, Moulton VR. Aging, immunity, and COVID-19: How age influences the host immune response to coronavirus infections? Front Physiol. 2020;11:571416.

35. Hou H, Wang T, Zhang B, Luo Y, Mao L, Wang F, et al. Detection of IgM and IgG antibodies in patients with coronavirus disease 2019. Clin Transl Immunol. 2020;9(5):e01136.

36. Use of convalescent plasma for COVID-19 in India: A review \& practical guidelines. 2021 [cited $2021 \mathrm{Feb} 16$ ]; Available from: https://www.ijmr.org.in/preprintarticle.asp?id=308620;type=0

Publisher's Note Springer Nature remains neutral with regard to jurisdictional claims in published maps and institutional affiliations. 